\title{
AMPUTATION OF THE LOWER LIMB FOR ISCHAEMIC DISEASE-A STUDY OF THE FUNCTIONAL RESULTS
}

\author{
L. R. DeJode, M.B., B.S., F.R.C.S.* \\ Formerly Senior Surgical Registrar, \\ The London Hospital, E.1.
}

Amputation of a limb is a serious and irrevocable step, to be undertaken only when no other course of action is possible. Despite recent advances in arterial surgery, amputations will continue to be necessary and although there has been recent interest in the Stokes Gritti (Martin and Wickham, 1962) and Through Knee techniques (Gillis, 1961), many surgeons continue to remove the leg at the standard above and below knee sites. Despite the large number of these amputations which are performed and the considerable expenditure which is involved in the provision of artificial limbs, very little information is available as to what proportion of patients utilise their prostheses. Perlow (1962) found that although almost all below-knee amputees learned to walk, only about $30 \%$ returned to employment. In aboveknee amputees the corresponding figures were $40 \%$ and $10 \%$. In view of the inadequacy of the available information it was decided to survey the lower limb amputations performed at The London Hospital in the period covered by the years 1953 to 1962 , with particular reference to the patient's ability to make use of an artificial limb.

\section{Material}

The study is based on 110 patients, on whom 157 amputations were performed (Tables 1 (a) and 1 (b)). The second amputation usually involved the loss of the other limb at an interval of anything from 2 weeks to 9 years later, but in 15 cases a reamputation at a higher level was required because of failure of healing or an unsuitable stump. The majority of the amputations were of the standard above or below knee variety with stumps respectively 10-11 inches (25-27.5 cms.) and 4-5 inches (10-12.5 cms.) long. Occasionally the extent of gangrene necessitated a shorter stump, but these cases are not considered separately. Approximately equal anterior and posterior flaps were made and usually primary suture of the flaps was carried out with drains placed at each end of the suture line. These drains were generally removed by the 4th post-operative day. The flaps were left unsutured in grossly infected cases and a delayed primary suture was performed

\footnotetext{
* Present address: Whipps Cross Hospital, London, E.11.
}

4 or 5 days later. From the follow-up point of view $\stackrel{\vec{\omega}}{\circ}$ this did not affect the outcome, and these cases have $\bar{D}$ not been considered separately. In over three-quarters 3 of the cases frank gangrene was the reason for amputation while in the remainder a persistent painful $\triangleq$ ulcer eventually necessitated loss of the limb. A list is of the underlying pathological conditions is given in Table 2. It will be noted that a higher proportion os of patients suffering from diabetes or Buerger's 0 disease (thromboangiitis obliterans) were thought $\triangle$ suitable for below-knee amputation. The reason for $\overrightarrow{ }$ this is that in both of these conditions there is peripheral ischæmia out of proportion to the amount of obstruction which is present in the major vessels. In diabetes, peripheral neuritis often results in hypoæsthesia rendering the foot more liable to $\vec{\bullet}$ infection following minor trauma. Hyperglycxma causes infection to progress more rapidly than usua and soon a viable, reasonably well vascularised fo 0 will become gangrenous. In Buerger's disease the vascular damage is frequently confined to the calf or more distal vessels, leaving the major vessels unaffected. For these reasons a more distal amputation is usually considered as being more likely to $\mathbb{D}$ succeed in these conditions.

Of the survivors 17 patients died within the $\overrightarrow{\overrightarrow{0}}$ first post-operative year and since it often takes 3 up to a year to gain proficiency with an artificial limb, these patients have been excluded from the limb utilisation series. Reamputation 흠 at a higher level was performed on 12 cases during the first year, and in 10 cases a con- $\frac{9}{3}$ tralateral amputation was performed within $\mathrm{a}_{\mathrm{c}}$ year. This left 101 cases where utilisation of $\frac{\bigcirc}{3}$ one or two artificial limbs might reasonably have been expected and these patients have $\mathrm{S}$ been followed up. Most patients have been $\frac{}{0}$ seen by one of the authors, while the remainder have been contacted by letter. Where the patient has since died, the necessary information has been obtained from the relatives or from $N$ the general practitioner. Assessment of utilisa- $\omega$ tion of an artificial limb is often difficult because these patients are sometimes supplied ${ }^{\circ}$ with a limb, but for various reasons fail to use it regularly or abandon it later due to deteriora-? tion in health or morale. All of the patients who are classified as mobile have used their $\frac{\mathrm{D}}{\mathbb{D}}$ artificial limb or limbs for a period of at least $\stackrel{\oplus}{\odot}$ 
TABLE 1 (a) PATIENTS INVOLVED

$\begin{array}{lccc} & \text { Number } & \text { Deaths* } & \text { Mortality \% } \\ \text { Males } & 88 & 9 & 10.2 \\ \text { Females } & 22 & 3 & 13.6 \\ \text { Total } & 110 & 12 & 10.9\end{array}$

\begin{tabular}{|c|c|c|c|c|c|}
\hline \multirow{6}{*}{$\begin{array}{l}\text { Above Knee } \\
\text { Below Knee } \\
\text { Bilateral } \\
\text { Total }\end{array}$} & \multicolumn{5}{|c|}{ TABLE 1 (b) AMPUTATIONS } \\
\hline & Operations & Average age & Deaths* & Average age & Mortality \\
\hline & 104 & & 10 & 65 & \\
\hline & 47 & 55 & 1 & (77) & 2.13 \\
\hline & 3 & 5 & & (43) & 33.3 \\
\hline & ${ }_{*}^{157}$ & 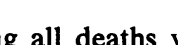 & 12 & & 1 \\
\hline
\end{tabular}

TABLE 2

\begin{tabular}{|c|c|c|c|c|c|}
\hline \multirow{5}{*}{$\begin{array}{l}\text { Pathology } \\
\text { Atheroma } \\
\text { Atheroma (diabetics) } \\
\text { Buerger's disease } \\
\text { Embolism }\end{array}$} & UNDERLYING & & & \\
\hline & Total & & ve knee & & w knee \\
\hline & 76 & 59 & $(77.6 \%)$ & 17 & $(22.4 \%)$ \\
\hline & 43 & 28 & $(65.1 \%)$ & 15 & (34.9\%) \\
\hline & $\begin{array}{r}34 \\
4\end{array}$ & $\begin{array}{r}20 \\
3\end{array}$ & (58.8\%) & 14 & $\begin{array}{l}(41.2 \%) \\
(25 \%)\end{array}$ \\
\hline & 157 & 110 & & 47 & \\
\hline & & & & & \\
\hline
\end{tabular}

TABLE 3

$\begin{array}{lcccc} & \text { Total } & \begin{array}{c}\text { Able to use } \\ \text { prosthesis }\end{array} & \begin{array}{c}\text { Wheelchair or } \\ \text { crutches }\end{array} & \text { Bedridden } \\ \text { Unilateral above knee } & 50 & 41 & 7 & 2 \\ \text { Unilateral below knee } & 21 & 19 & 2 & 3 \\ \text { Bilateral } & 30 & 15 & 12 & 3\end{array}$

one year. Prognosis was not affected by sex, so males and females are considered together. 18 patients appear under two headings. This occurs when contralateral amputation has been performed after a sufficiently long interval to allow utilisation of a single artificial limb, and a sufficient period of time has elapsed since the second amputation to assess utilisation of two artificial limbs.

\section{Results}

Overall results are shown in Table 1. As would be expected, below-knee amputations were performed more often in younger patients, and this is reflected in the lower mortality rate for this type of amputation. Most of the deaths were the result of congestive heart failure or bronchopneumonia in patients with generalised atheromatous disease who were often already debilitated as a result of gangrene or pain. Only one death could be directly attributed to operation. This was in a 64-year-old male where amputation was necessary due to infection of an arterial suture line following a bypass graft. He developed septicæmia as a result of infection of the stump and died 4 weeks after amputation.
Table 3 gives the results of the survey on prosthesis utilisation. The majority of aboveknee amputees were using the standard jointed prosthesis, but some of the older patients preferred to use a pylon permanently, and occasionally a special lightweight prosthesis was supplied. Of the bilateral cases, below-knee amputees were most likely to regain a useful degree of mobility, a remarkable example being an old lady of 72 who is able to do her own shopping. However even after bilateral aboveknee amputations, prostheses may be of value, as evidenced by two patients aged 60 who are still able to walk sufficiently to carry out light work. Several of the bilateral amputees who are unable to use a prosthesis are leading useful and interesting wheel chair lives.

The overall value of artificial limbs may be judged by the fact that of patients who were under the age of $65,83 \%$ (10 patients) of below-knee amputees and 60\% (26 patients) of above-knee amputees had been able to return to work. Roughly half of these patients had returned to their original occupation, while the remainder were performing either light unskilled work or had been retrained for a light skilled occupation. Of bilateral amputees 6 of 
the 11 aged less than 65 years had returned to work, all of course using invalid cars to reach their place of work.

\section{Discussion}

Many of the patients who come to amputation are weakened after months of pain and unsuccessful local treatment, and are often discouraged by failure of surgical attempts to save the limb. Amputation is regarded as a last resort and the patient is often given little hope of ever gaining mobility. A recent study of the emotional effects of lower-limb amputation (Caplan and Hackett, 1963) showed that in elderly patients the post-amputation period was characterised by feelings of hopelessness and impending death. Most of the patients maintained a facade of hope, the depression being openly expressed only as a mild apathy. The authors suggest that more attention be paid by the surgeon to the emotional aspects of amputation. Rehabilitation should start before the leg is amputated, emphasising to the patient that a useless burden is being lost and stressing the facilities for retraining. A visit from the social worker at this stage may be of considerable assistance to a patient who is still a wage earner, and it is surprising how a talk with a patient who is well advanced in rehabilitation can completely alter the individual's attitude to amputation. As regards technique, it is well worth taking time to correct anæmia and otherwise to improve the patient's general condition. According to Tolstedt and Bell (1962) the incidence of post-operative infection of the stump is the same whether or not peripheral tissue necrosis is present. This suggests that delay is not necessary in the presence of infection, but in such a case the use of prophylactic antibiotics is advisable. If infection is gross, delayed primary suture should be performed.

The choice of level is of great importance. As shown in this and other studies (Perlow, 1962) the patient with a below-knee amputation is more likely to make use of a prosthesis. However, in the present study it became apparent that the choice of level is of great importance. $73 \%$ of the above-knee amputation wounds healed uneventfully and without delay, but the corresponding figure after below-knee amputation was only $40 \%$. One-third of belowknee amputations eventually required conversion to above-knee. When the popliteal pulse is palpable the below-knee procedure is likely to succeed, and it is felt that only under this condition should the more conservative operation be performed. The popliteal pulse is however often difficult to feel, and even experienced observers find that it may vary considerably in strength from time to time. Perlow (1962) found that a preliminary lumbar sympathectomy appreciably increased the chances of success of below-knee amputation. In the present series the evidence on this point was inconclusive.

Stump exercises should be commenced as soon as possible after operation, and their importance emphasised to the patient. Contracture formation must not be allowed and since this seems particularly liable to occur in the time immediately after discharge from hospital and before walking training has commenced, supervision must be arranged during this period. Stump bandaging must be started as soon as the stitches are removed, and again the continuation of this important procedure must not be left to chance.

At this stage the patient is usually referred to the limb-fitting centre but the surgeon should continue to follow the patient's progress closely. Re-education in walking is best carried out in groups where the patient is able to see that his difficulties are not insurmountable and where competition plays an important part in stimulating progress. However, distance sometimes precludes regular attendance at a fitting centre, particularly for an elderly patient, and in this case the surgeon must see to it that walking exercises are arranged locally and must make himself responsible for the general health and morale of the patient. The general practitioner should be kept in touch with events: occasionally one finds that he has never been informed so that when the patient approaches him with some sort of problem he may feel that too great an effort is being required and advise discontinuation of the attempt to walk. This sort of conflicting advice destroys the patient's confidence. During walking re-education, angina of effort or intermittent claudication in the other leg often present problems. Whenever possible walking should be continued, with the tempo of activity related to the patient's capacity. As experience is gained in the use of a prosthesis, so less strain is involved in its manipulation and pain which appears likely to be crippling will lessen in severity, allowing a useful range of activity. Obviously the presence of claudication, angina or other disabilities such as hemiplegia strongly militate against the use of a prosthesis, and most of the failures in this series were due to one or other of these difficulties. However co-operation between the surgeon and the limb-fitting centre will often 
enable the patient who is on the point of abandoning the attempt to use a limb to become mobile with the aid of a lightweight limb or a pylon.

In many cases pylon wearing is established at 3 months and the patient is proficient in the use of an articulated prosthesis at 6 months after amputation. However these times are not infrequently doubled, particularly in elderly individuals or where there is delay in stump healing. Phantom pain does not seem to have been a serious problem in any of the cases under review and the occasional stump neuromas which gave rise to symptoms usually responded to physiotherapy. A phantom limb is always present but if its significance is explained to the patient it rarely remains a problem when walking is resumed.

Wherever possible an early decision should be made as to whether the patient is likely to use an artificial limb. If, as in the majority of cases, this seems probable then rehabilitation should be organised and pressed through with vigour. On the other hand if the attempt seems doomed to failure it is better to accept this from the start, spare the patient much needless effort and disappointment and concentrate on providing mobility in a wheelchair.

\section{Summary}

The results of 157 amputations of the lower limb performed during a 10 -year period are presented. There were 12 post-operative deaths and a further 17 patients died during the first post-operative year. Allowing for bilateral amputations this left 101 cases suitable for prosthesis utilisation follow-up.

After above-knee amputation the stump healed uneventfully in $73 \%$. After below-knee amputation the corresponding figure was only $40 \%$. Below-knee amputation is most likely to be a success in Buerger's disease, and should rarely be performed if the popliteal pulse is absent.

Given good management a surprisingly high proportion of amputees regain mobility. 60 of 71 unilateral, and 15 of 30 bilateral amputees were able to use a prosthesis to some extent. As would be expected, the younger patients adapted better to the use of an artificial limb, and a below-knee prosthesis proved to be easier to manage.

We would like to thank the many members of the staff of the London Hospital who have been responsible for the care of these patients and who have given permission for us to use their cases. In particular we would like- to thank Mr. E. C. B. Butler whose follow-up clinic greatly simplified the task of collecting the information.

\section{REFERENCES}

Caplan, L. M., and HacketT, T. P. (1963): Effects of Amputation, New Engl. J. Med., 269, 1166.

GILlIS, L. (1961): Communication, Brit. med. J., ii, 1355 .

Martin, P., and Wickham, J. E. A. (1962): Gritti-cê Stokes Amputation for Atherosclerotic Gangrene, Lancet, ii, 16.

PERLOW, S. (1962): Amputation for Gangrene because of Occlusive Arterial Disease, Amer. J. Surg., $103,569$.

Tolstedt, G. E., and Bell, J. W. (1962): Sepsis and Survival after Above Knee Amputation, Amer. J. Surg., 103, 372. 